\title{
Bovine Tuberculosis in Cattle in the Highlands of Cameroon: Seroprevalence Estimates and Rates of Tuberculin Skin Test Reactors at Modified Cut-Offs
}

\author{
J. Awah-Ndukum, ${ }^{1,2,3}$ A. C. Kudi, ${ }^{3,4}$ G. S. Bah, ${ }^{5}$ G. Bradley, ${ }^{3}$ S. F. Tebug, ${ }^{6}$ P. L. Dickmu, ${ }^{7}$ \\ H. N. Njakoi, ${ }^{8}$ and W. N. Agharih' \\ ${ }^{1}$ School of Veterinary Medicine and Sciences, University of Ngaoundere, Ngaoundere, Adamawa Region, Cameroon \\ ${ }^{2}$ Department of Animal Sciences, University of Dschang, Dschang, West Region, Cameroon \\ ${ }^{3}$ School of Biomedical and Biological Sciences, University of Plymouth, Plymouth, PL4 8AA, UK \\ ${ }^{4}$ Department of Veterinary Medicine, Ahmadu Bello University, Zaria, Kaduna State, Nigeria \\ ${ }^{5}$ Institute of Agricultural research for Development (IRAD), Wakwa- Ngaoundere, Adamawa Region, Cameroon \\ ${ }^{6}$ Institute of Animal Breeding and Husbandry, University of Kiel, Kiel, Germany \\ ${ }^{7}$ Department of Mathematics and Computer Science, University of Dschang, Dschang, West Region, Cameroon \\ ${ }^{8}$ Heifer Project International, P.O. Box 467, Bamenda, North West Region, Cameroon \\ ${ }^{9}$ Delegation of Livestock, Fisheries and Animal Husbandry, North West Region, Cameroon
}

Correspondence should be addressed to J. Awah-Ndukum, awahndukum@yahoo.co.uk

Received 19 October 2011; Revised 10 January 2012; Accepted 22 January 2012

Academic Editor: Jesse M. Hostetter

Copyright (C) 2012 J. Awah-Ndukum et al. This is an open access article distributed under the Creative Commons Attribution License, which permits unrestricted use, distribution, and reproduction in any medium, provided the original work is properly cited.

\begin{abstract}
The aim of this study was to obtain epidemiological estimates of bovine tuberculosis (TB) prevalence in cattle in the highlands of Cameroon using two population-based tuberculin skin test (TST) surveys in the years 2009 and 2010. However, prior to the TST survey in 2010, blood was collected from already chosen cattle for serological assay. Anti-bovine TB antibodies was detected in $37.17 \%$ of tested animals and bovine TB prevalence estimates were $3.59 \%-7.48 \%, 8.92 \%-13.25 \%, 11.77 \%-17.26 \%$ and $13.14 \%-$ $18.35 \%$ for comparative TST at $\geq 4 \mathrm{~mm}, \geq 3 \mathrm{~mm}$ and $\geq 2 \mathrm{~mm}$ cut-off points and single TST, respectively. The agreement between TST and lateral flow was generally higher in TST positive than in TST negative subjects. The $K$ coefficients were $0.119,0.234,0.251$ and 0.254 for comparative TST at $\geq 4 \mathrm{~mm}, \geq 3 \mathrm{~mm}$ and $\geq 2 \mathrm{~mm}$ cut-off points and the single TST groups, respectively. Chi square statistics revealed that strong $\left(P<0.05 ; \chi^{2}>48\right)$ associations existed between seroprevalence rates and TST reactors. The study suggested that using lateral flow assay and TST at severe interpretations could improve the perception of bovine TB in Cameroon. The importance of defining TST at modified cut-offs and disease status by post-mortem detection and mycobacterial culture of TB lesions in local environments cannot be overemphasised.
\end{abstract}

\section{Introduction}

Bovine tuberculosis (TB) is a zoonotic disease with severe public health significance but it is neglected in Cameroon. The tuberculin skin tests (TSTs) are currently the best available techniques for international field diagnosis of bovine $\mathrm{TB}$ in live animals $[1,2]$ and it is based on delayed hypersensitivity reactions [3]. The single intradermal comparative cervical tuberculin (SICCT) test involving the intradermal injection of bovine tuberculin (BT) and avian tuberculin (AT) at separate sites in the skin of the neck gives more specific results than the single intradermal tuberculin (SIT) test which uses only BT $[4,5]$. TST can effectively detect early stages of $M$. bovis infection in cattle and allows for rapid removal of infected animals, limited transmission, and fast eradication of bovine TB [6]. There are OIErecommended cutoff points of the increase in skin thickness for SICCT-BT and SIT-BT to be positive [3]. However, the OIE-recommended cutoff values were established mainly in developed countries for Bos taurus cattle, and different cutoff 
values are applied according to a particular country's disease status and objective of its disease control programme $[4,7-$ 9].

The performance of TST could be affected by environmental factors, host factors (status of immunity, genetics), and nature of the tuberculin used $[1,4,5,9]$. A perfect cutoff point in a specific geographic area may not be so useful in another environment $[1,4]$. Also, the ability of the test to predict positive disease status depends on its sensitivity and specificity and prevalence of the disease in tested population [1]. Anergic animals, animals exhibiting reactions to both avian and mammalian tuberculins, animals in advanced stage of disease, periparturient cows, and animals with confined infection notably in the udder and with localised infection often in the lymphatic glands that has become inactive (latent) have been reported to be poor responders to TST [10]. However, severe interpretations are done in regions or herds where $M$. bovis infection has been confirmed, and SIT-BT reactors may also be subjected to an SICCTBT test, based on the discretion of the veterinarian [4]. Veterinarians continue to play pivotal roles in inspections of animal (antemortem and postmortem) and animal products, diagnosis of $M$. bovis infected cattle, and impacting of cattle producers in bovine TB eradication programs [11]. Postmortem detection of TB lesions and other bovine TB diagnostic techniques (e.g., gamma-Interferon, ESAT-6 tests, serologic and fluorescence polarization assays) have been used to determine the ability of TST in the diagnosis of bovine TB in cattle in different environmental conditions around the world, including parts of Africa $[1,2,6,7,9$, 12-16]. However, TST-negative animals at slaughter with evidence of encapsulated lesions confirmed as caused by $M$. bovis have also been reported [10].

TST may demand physical exertion in the field but it is also simple and relatively inexpensive and offers reliable means of screening cattle populations in an entire region $[4,6]$. Ancillary tests are being used and/or currently being validated to improve diagnosis and reduce the number of false positive results following TST $[1,2,6,7]$. Also, rapid and simple immune-chromatographic assays for the serodiagnosis of bovine TB have been developed $[17,18]$ and proposed as additional tests to the TST for antemortem diagnosis $[2,19,20]$. These chromatographic immunoassays employ unique cocktails of selected $M$. bovis antigens as both qualitative captures and detectors of specific antibodies against $M$. bovis in plasma, serum, and whole blood [17, 21]. MPB83, ESAT-6, 14-kDa protein, CFP-10, MPB70, MPT63, MPT51, MPT32, MPB59, MPB64, Acr1, PstS-1, M. bovis purified protein derivatives, ESAT-6/CFP10 fusion protein, $16-\mathrm{kDa}$ alpha-crystallin/MPB83 fusion protein, and $M$. bovis culture filtrate have been identified as the common seroreactive antigens in bovine TB $[17,18,22]$. The bound antibodies are visualized with the naked eye as colour band at the test device within some minutes of application $[17,21]$. The assay requires no specific expertise or equipment, and the test kit may be kept without the need for refrigeration $[17,18,21]$.

There are scanty reports of bovine TB prevalence in Cameroon, modifications of the OIE standards of TST applied elsewhere have been used to estimate the disease status in cattle in the country, and the findings have varied widely, even for the same sites [23-27]. This study was carried out to investigate bovine TB prevalence in cattle in the highlands of Cameroon through seroprevalence estimations, rates of TST reactors at modified cutoff points, and the epidemiological usefulness of the proposed screening algorithms. TST data of tested cattle in the years $2009(n=$ $2,853)$ and $2010(n=1,381)$ were reanalyzed, and the epidemiological implication for applying TST at various cutoff points for a predominantly Zebu cattle population was discussed.

\section{Materials and Methods}

2.1. Study Area and Population. Cattle populations in the Western highlands $\left(5^{\circ}-7^{\circ} \mathrm{N}\right.$ and $\left.10^{\circ}-11^{\circ} \mathrm{E}\right)$ and Adamawa plateaux $\left(6-7^{\circ} 30^{\prime} \mathrm{N}\right.$ and $\left.12^{\circ} 30^{\prime}-14^{\circ} \mathrm{E}\right)$ of Cameroon (Figure 1) were sampled in the years 2009 and 2010 as part of a bovine TB prevalence study. A SIT bovine TB prevalence rate of $26 \%$ recorded by Muchaal [25] in the Western highlands of Cameroon was used to estimate the number of cattle required to detect $\geq 1$ positive reactor with a desired $95 \%$ confidence and precision of $5 \%$ as previously described [28]. The selection of cattle herds was done by the random-number generation method of cattle keeping communities, cattle owners, and locations of herds from records of annual livestock vaccination campaigns (contagious bovine pleuropneumonia, pasteurellosis, black quarter) at the Regional Delegations of MINEPIA (Ministère de l'Elevage, des Pêches et des Industries Animales (Ministry of Livestock, Fisheries and Animal Industries)). All animals within selected herds were tested except recently calved cows (within 2 months postpartum) and calves less than 6 months old because of immunosuppression in lactating cows and high maternal antibodies in calves that desensitizes them to tuberculin $[29,30]$.

During March to September 2009, a total of 2,853 cattle (84 herds) were tested in five administrative divisions in the Northwest regions of the Western highlands (Donga and Matung, Menchum, Bui, Mezam and Boyo) and one division in the Adamawa plateaux (Vina) of Cameroon (Figure 1). Similarly, 1,381 cattle (40 herds) were tested during May to September 2010 in Mezam and Bui divisions in the Western highlands which showed high bovine TB prevalence rates in the previous survey and also in the Vina division in the Adamawa plateaux. However, 30-60 minutes prior to the TST carried out in the year 2010, blood was collected from 807 cattle in 20 randomly selected herds of the 40 already chosen herds $(1,381$ cattle) to extract serum for lateral flow assay of antibovine TB antibodies (Antibovine TB Ab).

Risk assessments were done to avoid hazards to all persons and animals involved in the project. The project approval and ethical clearances were obtained from the required authorities in Cameroon including the National Ethics Committee, regional delegations of MINEPIA in the Northwest and Adamawa regions. The purpose of the study was explained to the targeted participants usually with 


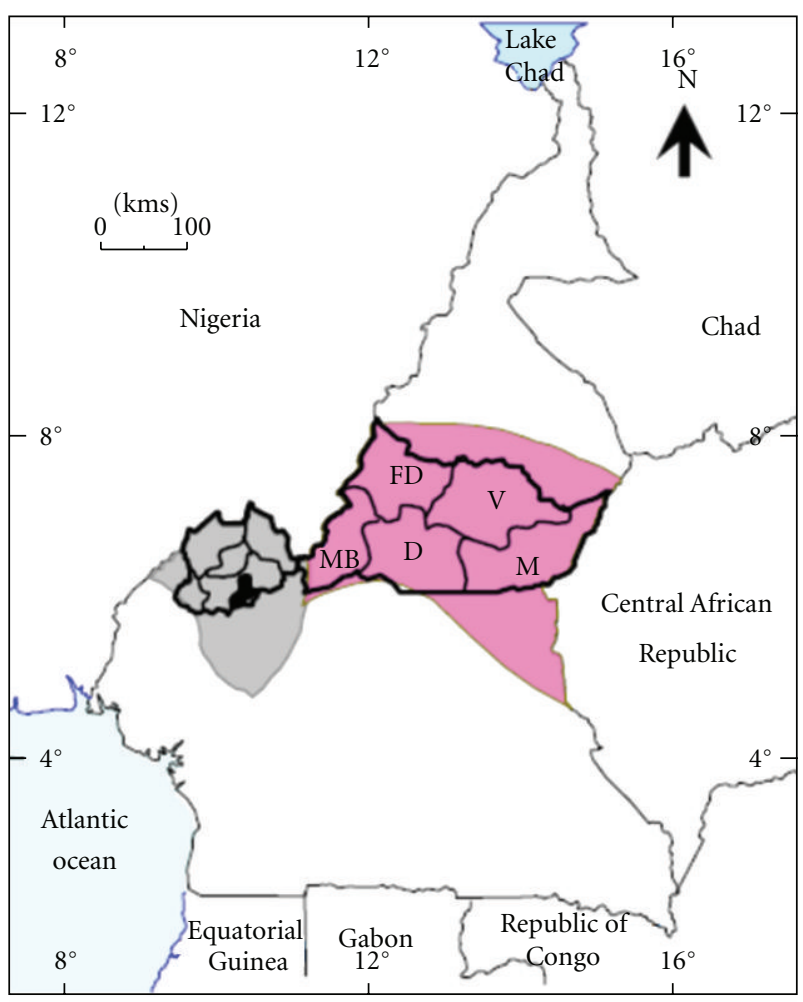

Agroecological highland zones

$\square$ Guinea savannah highlands (Adamawa plateaux)

Sudano-guinean highlands (Western highlands)

FIGURE 1: Map of Cameroon showing administrative regions within the Northwest and Adamawa Regions. Divisions in Northwest region are Donga and Matung, Menchum, Bui, Mezam, Boyo, and Ngo-Ketunja (shaded and not used in this study). Divisions in Adamawa region are V: Vina (study area); M: Mbere; D: Djerem; MB: Mayo-Banyo; FD: Faro et Deo.

the assistance of resident veterinarians, local community leaders, and trusted intermediaries. A herd was tested after an informed consent was given by the owner. Apart from minor jugular vein puncture for blood collection, intradermal injections of AT and $\mathrm{BT}$, and procedural restraining manipulations for safety purposes, the animals were not subjected to suffering.

2.2. Antibovine Tuberculosis Antibody Assay. About $5 \mathrm{~mL}$ of blood was collected by jugular venipuncture of 807 cattle (20 herds) to extract serum for the detection of antibovine $\mathrm{TB}$ Ab against the $M$. bovis MPB70 antigen using the rapid lateral-flow test (Anigen Bovine $\mathrm{Tb} \mathrm{Ab}$, BioNote Inc., Republic of Korea), as described by the manufacturer. The immunochromatographic assay using recombinant MPB70 antigen as capture and detector in a direct sandwich method detected antibodies (IgM, IgG) against $M$ bovis. Briefly, in the ready-to-use disposable test kit, $10 \mu \mathrm{L}$ of test serum was poured into the sample well, and after 1 minute, 3 drops of developing buffer (provided as part of the kit) were placed in the buffer well. The result was interpreted after 20 minutes. The presence of two purple coloured bands within the result window, the test area and control line, indicated antibodies positive result whereas no band in the test area in addition to a visible control purple line was negative. An invalid test was one where no coloured band was visible within the result window. The appearance of a control colour band, for positive or negative assays, indicated that the test was working properly.

2.3. Tuberculin Skin Tests and Classification of Reactors. TSTs were carried out in the selected cattle $(2,583$ in the year 2009 and 1,381 in the year 2010 including the 807 blood donors but after blood collection) by intradermal injections of $0.1 \mathrm{~mL}$ each of AT (2500 IU/dose) and BT (3000 IU/dose) in two sites, at $12 \mathrm{~cm}$ apart in the right neck region. A correct intradermal injection was confirmed by palpating a small grain-like swelling at each injection site. The skin thickness was measured prior to and 72 hours after injecting the tuberculins using a digital calliper. The OIErecommended $\geq 4 \mathrm{~mm}$ cutoff point of increase in skin fold thickness [3] as well as $\geq 3 \mathrm{~mm}$ and $\geq 2 \mathrm{~mm}$ cutoff points was assessed for SICCT-BT reactor status. The corresponding ranges $\geq 1 \mathrm{~mm}$ to $<4 \mathrm{~mm}, \geq 1 \mathrm{~mm}$ to $<3 \mathrm{~mm}$, and $\geq 1 \mathrm{~mm}$ to $<2 \mathrm{~mm}$ were classified as doubtful responses, respectively. SICCT-BT was noted as negative if the skin response was $<1 \mathrm{~mm}$. SIT-BT interpretations were done using skin fold thickness of $\geq 4 \mathrm{~mm}, \geq 2 \mathrm{~mm}$ to $<4 \mathrm{~mm}$, and $<2 \mathrm{~mm}$ for positive, doubtful, and negative responses, respectively [3]. These cutoff points were assessed against the demonstrated circulating antibovine $\mathrm{Tb}$ antibodies status and classified as adapted from Martrenchar et al. [23] to determine the cutoff zone and risk group of TST reactors for consideration (Figure 2).

2.4. Data Management and Statistical Analysis. The lateral flow assay results and TST data at the $\geq 2 \mathrm{~mm}, \geq 3 \mathrm{~mm}$, and $\geq 4 \mathrm{~mm}$ cutoff points for individual cattle were entered into Microsoft Excel (Microsoft Corporation, USA) and also exported to SigmaPlot (Systat Software Inc, USA) for further analysis. The seroprevalence estimates, rates of TST reactors in the tested cattle population, and agreement between both methods at the predefined cutoff points were assessed [28].

The predictive values and diagnostic likelihood ratios of TST at the various cutoff points were compared against the antibovine $\mathrm{TB} \mathrm{Ab}$ assay [28]. With sensitivity and specificity values obtained by Ameni et al. [9] and Pollock et al. [12], the observed prevalence rates were corrected using the Roganand-Gladen formula $[28,31]$. The kappa statistics was used to estimate the degree of agreements between both tests while Chi-square techniques were applied to compare individual and herd prevalence of reactors in the different variables [28, 32]. where

The figure was adapted from Martrenchar et al. [23]

(i) $\mathrm{BT}=\left(\mathrm{BT}_{72}-\mathrm{BT}_{0}\right)$ is the skin fold thickness at the injection site of bovine tuberculin at 72 hours; 


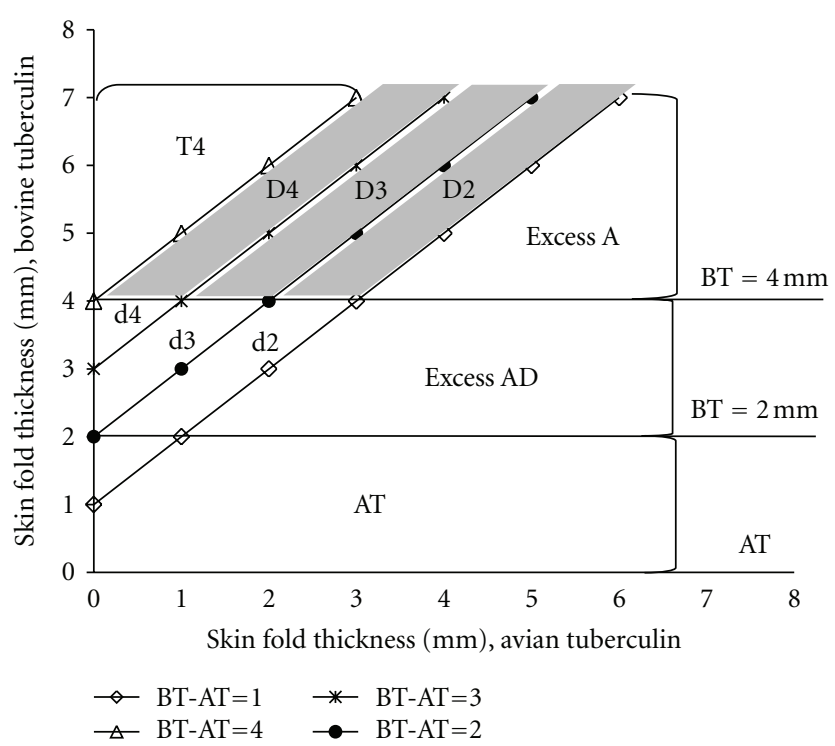

Figure 2: Classification of cattle according to their possible tuberculin skin tests response at $\geq 4 \mathrm{~mm}, \geq 3 \mathrm{~mm}$, and $\geq 2 \mathrm{~mm}$ cutoff points.

(ii) $\mathrm{AT}=\left(\mathrm{AT}_{72}-\mathrm{AT}_{0}\right)$ is the skin fold thickness at the injection site of avian tuberculin at 72 hours;

(iii) $(\mathrm{D}+\mathrm{d})$ is the SICCT-BT doubtful responses; the skin responses $(\mathrm{D} 2+\mathrm{d} 2),(\mathrm{D} 3+\mathrm{D} 2+\mathrm{d} 3+\mathrm{d} 2)$, and $(\mathrm{D} 4+\mathrm{D} 3+\mathrm{D} 2+\mathrm{d} 4+\mathrm{d} 3+\mathrm{d} 2)$ are for $\geq 1 \mathrm{~mm}$ to $<2 \mathrm{~mm}, \geq 1 \mathrm{~mm}$ to $<3 \mathrm{~mm}$, and $\geq 1 \mathrm{~mm}$ to $<4 \mathrm{~mm}$ cutoff ranges, respectively;

(iv) Excess $\mathrm{d} 4(\mathrm{Xd} 4)=\mathrm{d} 4+\mathrm{d} 3+\mathrm{d} 2$ is the SICCT-BT doubtful responses ( $\geq 4 \mathrm{~mm}$ cutoff point) and classified as SIT-BT doubtful responses (when $1 \mathrm{~mm} \leq$ $(\mathrm{BT}-\mathrm{AT})<4 \mathrm{~mm}$ and $2 \mathrm{~mm} \leq \mathrm{BT}<4 \mathrm{~mm}$ );

(v) Excess $\mathrm{d} 3(\mathrm{Xd} 3)=\mathrm{d} 3+\mathrm{d} 2$ is the SICCT-BT doubtful responses ( $\geq 3 \mathrm{~mm}$ cutoff point) and classified as SITBT doubtful responses (when $1 \mathrm{~mm} \leq(\mathrm{BT}-\mathrm{AT})<$ $3 \mathrm{~mm}$ and $2 \mathrm{~mm} \leq \mathrm{BT}<4 \mathrm{~mm}$ );

(vi) Excess $\mathrm{d} 2(\mathrm{Xd} 2)=\mathrm{d} 2$ is the SICCT-BT doubtful responses ( $\geq 2 \mathrm{~mm}$ cutoff point) and classified as SITBT doubtful responses (when $1 \mathrm{~mm} \leq(\mathrm{BT}-\mathrm{AT})<$ $2 \mathrm{~mm}$ and $2 \mathrm{~mm} \leq \mathrm{BT}<4 \mathrm{~mm}$ );

(vii) Excess D4 $(\mathrm{XD} 4)=(\mathrm{D} 4+\mathrm{D} 3+\mathrm{D} 2)$ is the SICCT-BT doubtful responses at $\geq 4 \mathrm{~mm}$ cutoff point and classed as SIT-BT-positive animals (when $1 \mathrm{~mm} \leq(\mathrm{BT}-\mathrm{AT})$ $<4 \mathrm{~mm}$ and $\mathrm{BT} \geq 4 \mathrm{~mm})$;

(viii) Excess D3 $(\mathrm{XD} 3)=(\mathrm{D} 3+\mathrm{D} 2)$ is the SICCT-BT doubtful responses at $\geq 3 \mathrm{~mm}$ cutoff point and classed as SIT-BT-positive animals (when $1 \mathrm{~mm} \leq(\mathrm{BT}-\mathrm{AT})$ $<3 \mathrm{~mm}$ and $\mathrm{BT} \geq 4 \mathrm{~mm})$;

(ix) Excess D2 (XD2) $=($ D2) is the SICCT-BT doubtful responses at the $\geq 2 \mathrm{~mm}$ cutoff point and classed as SIT-BT-positive animals (when $1 \mathrm{~mm} \leq(\mathrm{BT}-\mathrm{AT})<$ $2 \mathrm{~mm}$ and $\mathrm{BT} \geq 4 \mathrm{~mm}$ ); (x) T4 is the SICCT-BT-positive animals at $\geq 4 \mathrm{~mm}$ cutoff point (when $(\mathrm{BT}-\mathrm{AT}) \geq 4 \mathrm{~mm}$ );

(xi) $\mathrm{T} 3=(\mathrm{T} 4+\mathrm{XD} 4+\mathrm{Xd} 4)$ is the SICCT-BT-positive animals at $\geq 3 \mathrm{~mm}$ cutoff point (when $(\mathrm{BT}-\mathrm{AT}) \geq$ $3 \mathrm{~mm})$;

(xii) $\mathrm{T} 2=(\mathrm{T} 3+\mathrm{XD} 3+\mathrm{Xd} 3)$ is the SICCT-BT-positive animals at $\geq 2 \mathrm{~mm}$ cutoff point (when $(\mathrm{BT}-\mathrm{AT}) \geq$ $2 \mathrm{~mm})$;

(xiii) Excess A (XA) is the animals classed as SIT-BTpositive animals and infected with atypical mycobacteria according to SICCT-AT (when BT $\geq 4 \mathrm{~mm}$ and $(\mathrm{BT}-\mathrm{AT})<1 \mathrm{~mm})$;

(xiv) Excess $\mathrm{AD}$ (XAD) is the animals classed as SITBT doubtful responses and infected with atypical mycobacteria according to SICCT-AT (when $2 \mathrm{~mm} \leq$ $\mathrm{BT}<4 \mathrm{~mm}$ and $(\mathrm{BT}-\mathrm{AT})<1 \mathrm{~mm}) ;$

(xv) AT is the animals infected with atypical mycobacteria according to SICCT-AT and classed as SIT-BT negative animals (when $\mathrm{BT}<2 \mathrm{~mm}$ and $(\mathrm{AT}-\mathrm{BT})>$ $0 \mathrm{~mm})$.

\section{Results}

3.1. Observed Prevalence Rates and Agreements between Lateral Flow Assay and Tuberculin Skin Tests at $\geq 2 \mathrm{~mm}$, $\geq 3 \mathrm{~mm}$, and $\geq 4 \mathrm{~mm}$ Cutoff Points. The observed TST results at modified cutoff points and antibovine TB Ab assay in 807 cattle are summarized in Table 1. Of 807 tested cattle, antibovine $\mathrm{TB} \mathrm{Ab}$ was detected in 37.17\% (95\% CI: 30.64-43.71) while 11.77\% (95\% CI: 9.55-14.00), $8.92 \%$ (95\% CI: 6.96-10.88), and 3.59\% (95\% CI: 2.31-4.88) of them were SICCT-BT positive at $\geq 2 \mathrm{~mm}, \geq 3 \mathrm{~mm}$, and $\geq 4 \mathrm{~mm}$ cutoff points, respectively. The proportion of SICCTBT/antibovine $\mathrm{TB} \mathrm{Ab}$ reactors was highest $(P<0.05)$ at the $\geq 2 \mathrm{~mm}(9.42 \%$ (95\% CI: 7.40\%-11.43\%)) followed by the $\geq 3 \mathrm{~mm}$ (7.93\% (95\% CI: 6.07-9.79)) and $\geq 4 \mathrm{~mm}(3.59 \%$ (95\% CI: $2.31 \%-4.88 \%)$ ) cutoff point groups.

However, analysis of all antibovine TB Ab reactors (300) revealed that $25.33 \%, 21.33 \%, 9.67 \%$, and $27 \%$ of them were positive at the SICCT-BT $\geq 2 \mathrm{~mm}, \geq 3 \mathrm{~mm}$, and $\geq 4 \mathrm{~mm}$ cutoff points and SIT-BT, respectively. The proportion of SICCT-BT doubtful/antibovine $\mathrm{TB} \mathrm{Ab}$ positive reacting cattle was highest $(P<0.05)$ at the SICCT-BT $\geq 4 \mathrm{~mm}$ (21\%) followed by the $\geq 3 \mathrm{~mm}(5.67 \%)$ and $\geq 2 \mathrm{~mm}(1.67 \%)$ cutoff point groups. However, $0.62 \%$ (95\% CI: $0.08 \%-$ $1.16 \%$ ), 3.47\% (95\% CI: $2.21 \%-4.73 \%$ ), and $8.80 \%$ (95\% CI: $6.84 \%-10.75 \%)$ of the 807 tested cattle showed SICCT-BT inconclusive results while $0.62 \%$ (95\% CI: $0.08 \%-1.16 \%)$, $2.11 \%$ (95\% CI: 1.12\%-3.10\%), and 7.81\% (95\% CI: 5.96\%$9.66 \%$ ) reactors were SICCT-BT doubtful and antibovine $\mathrm{TB} \mathrm{Ab}$ positive at the o $2 \mathrm{~mm}, \geq 3 \mathrm{~mm}$, and $\geq 4 \mathrm{~mm}$ cutoff points, respectively. Over 27.14\% (95\% CI: $24.07 \%-30.21 \%$ ) negative SICCT-BT reactors were also positive for antibovine TB Ab.

Furthermore, 13.14\% (95\% CI: 10.80\%-15.47\%) SITBT and $10.04 \%$ (95\% CI: 7.96-12.11) SIT-BT positive/antibovine TB-Ab-positive animals were recorded. 


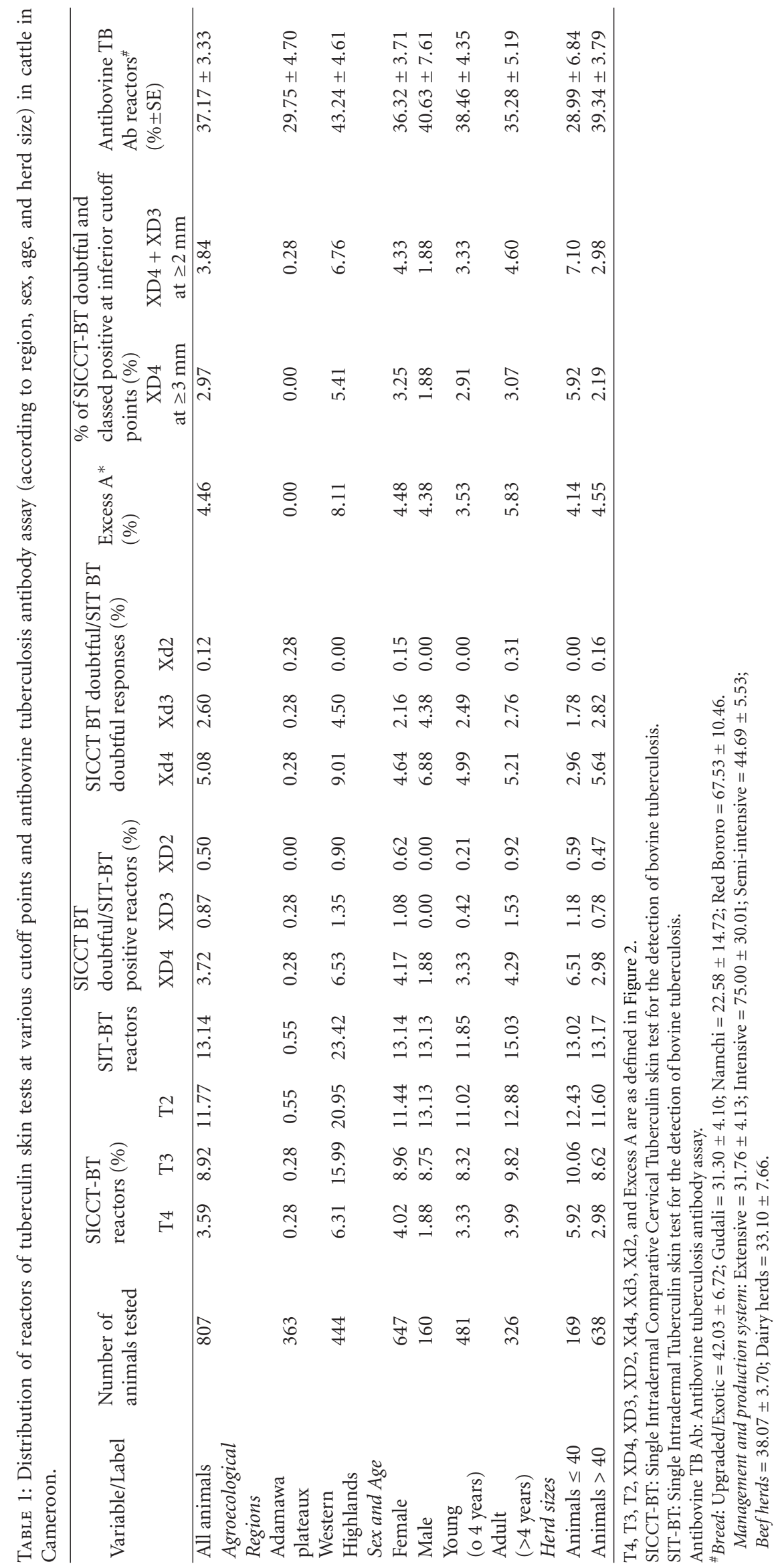


TABle 2: Agreement between reactors of tuberculin skin tests and antibovine tuberculosis antibody assay according to various tuberculin skin response cutoff points.

\begin{tabular}{|c|c|c|c|c|c|c|c|c|}
\hline & \multicolumn{6}{|c|}{ SICCT-BT cutoff points } & \multirow{2}{*}{\multicolumn{2}{|c|}{$\begin{array}{l}\text { SIT-BT } \\
\geq 4 \mathrm{~mm}\end{array}$}} \\
\hline & \multicolumn{2}{|c|}{$\geq 4 \mathrm{~mm}$} & \multicolumn{2}{|c|}{$\geq 3 \mathrm{~mm}$} & \multicolumn{2}{|c|}{$\geq 2 \mathrm{~mm}$} & & \\
\hline & Number & $\%$ & Number & $\%$ & Number & $\%$ & Number & $\%$ \\
\hline TST positive/Anti-BTB Ab positive & 29 & 3.59 & 64 & 7.93 & 76 & 9.42 & 81 & 10.04 \\
\hline TST negative ${ }^{\# / A n t i-B T B ~ A b ~ p o s i t i v e ~}$ & 271 & 34.82 & 236 & 29.24 & 224 & 27.76 & 219 & 27.14 \\
\hline TST positive/Anti-BTB Ab negative & 0 & 0 & 8 & 0.99 & 19 & 2.35 & 25 & 3.10 \\
\hline TST negative ${ }^{\#} /$ Anti-BTB Ab negative & 507 & 62.83 & 499 & 61.83 & 488 & 60.47 & 482 & 59.73 \\
\hline Total & 807 & & 807 & & 807 & & 807 & \\
\hline Agreement & $29 / 807$ & 3.59 & $64 / 807$ & 7.93 & $76 / 807$ & 9.42 & $81 / 807$ & 10.04 \\
\hline Kappa statistics* & 0.1 & & 0.2 & & 0.2 & & 0.2 & \\
\hline
\end{tabular}

TST: Tuberculin skin test.

Anti-BTB Ab: antibovine tuberculosis antibody assay.

\#Not TST positive including TST doubtful reactors.

* Kappa ranges from 1 (complete agreement beyond chance) to 0 (agreement is equal to that expected by chance), whereas negative values indicate that agreement less than that is expected by chance.

Among the SIT-BT reactors, $76.42 \%$ of them were antibovine $\mathrm{TB} \mathrm{Ab}$ reactors and over $89.62 \%, 67.92 \%$, and $27.36 \%$ were SICCT-BT reactors while $71.70 \%, 60.38 \%$, and $27.36 \%$ were SICCT-BT-positive/antibovine TB-Ab-positive animals at the $2 \mathrm{~mm} ; \geq 3 \mathrm{~mm}$, and $\geq 4 \mathrm{~mm}$ cutoff points, respectively. Overall, 31 (3.84\%) SICCT-BT doubtful/SIT-BT-positive animals at superior cutoff points were classified as SICCTBT reactors at $\geq 3 \mathrm{~mm}(2.97 \%)$ and $\geq 2 \mathrm{~mm}(3.84 \%)$ cutoff points (Table 1).

The agreement between TST at modified cutoff points and antibovine TB antibody assay was shown in Table 2. In all, the concordances (TST positive/antibovine $\mathrm{TB} \mathrm{Ab}$ positive) were $100 \%, 88.89 \%, 80 \%$, and $76.42 \%$ in positive subjects at SICCT-BT $\geq 4 \mathrm{~mm}, \geq 3 \mathrm{~mm}$, and $\geq 2 \mathrm{~mm}$ cut-offs and SIT-BT, respectively. The discordances (TST negative/antibovine $\mathrm{TB} \mathrm{Ab}$ positive) were $34.83 \%, 32.11 \%$, $31.46 \%$, and $31.24 \%$, at the SICCT-BT $\geq 4 \mathrm{~mm}, \geq 3 \mathrm{~mm}$, and $\geq 2 \mathrm{~mm}$ cutoff points and SIT-BT, respectively. However, the concordances (TST positive/antibovine TB Ab positive) in antibovine $\mathrm{TB} A \mathrm{Ab}$ positive subjects were 9.67\%, $21.33 \%, 25.33 \%$, and $27 \%$ while the discordances (TST negative/antibovine $\mathrm{TB}$ Ab positive) were $94 \%, 78.67 \%, 74.67 \%$, and $73 \%$, at the SICCT-BT $\geq 4 \mathrm{~mm}, \geq 3 \mathrm{~mm}$, and $\geq 2 \mathrm{~mm}$ cutoff points and SIT-BT, respectively. The bench marks (>0.80: very good agreement; $0.61-0.80$ : good agreement; 0.41-0.60: moderate agreement; $0.21-0.40$ fair agreement and $\leq 0.20$ : poor agreement) for evaluating points estimates of kappa values [28] revealed a poor agreement between SICCT-BT test and antibovine TB Ab assay at the $\geq 4 \mathrm{~mm}$ skin response cutoff point and fair agreements at the other cutoff points ( $\geq 3 \mathrm{~mm}$ and $\geq 2 \mathrm{~mm}$; and SIT-BT).

\subsection{Comparison of Tuberculin Skin Tests at Modified Cutoff} Points and Lateral Flow Assay in Cattle Reactors. The predictive values and likelihood ratios of SICCT-BT at various cutoff values and SIT-BT in cattle reactors against the antibovine $\mathrm{TB}$ Ab assay are shown in Table 3. Strong associations were noted between the seroprevalence estimates and rates of TST reactors irrespective of the TSTS cut-off value $(P<0.05$; $\left.\chi^{2}>48\right)$ in this study. However, decreasing the cutoff points revealed inverse relationships with test predictive values and diagnostic likelihood ratios. The ability of SICCT-BT to produce no false negative result increased with increase in cutoff point (nonsignificant differences were noted between the $\geq 2 \mathrm{~mm}$ versus $\geq 3 \mathrm{~mm}$ and $\geq 3 \mathrm{~mm}$ versus $\geq 4 \mathrm{~mm}$ cutoff points). The findings also suggested that prediction of disease status improved with severe interpretation of TST (decreasing cutoff point). The study indicated that using antibovine $\mathrm{TB} \mathrm{Ab}$ assays as ancillary diagnostic tests to SICCT-BT in cattle could significantly improve diagnosis of bovine TB cases. Statistically, the best all round SICCT-BT performance was realized at the $\geq 3 \mathrm{~mm}$ cutoff point. However, the $\geq 2 \mathrm{~mm}$ cut-off value showed the highest positive predictive value and a comparable positive diagnostic likelihood ratio to the others.

The detection of antibovine $\mathrm{TB} \mathrm{Ab}$ positive cattle and proportions of SICCT-BT reactors and antibovine TB $\mathrm{Ab} / \mathrm{SICCT}-\mathrm{BT}$ reactors at the different cut-offs are shown in Figure 4. The SICCT-BT $\geq 2 \mathrm{~mm}$ cutoff value gave the highest $(P<0.05)$ rate $(23.60 \%)$ followed by the $\geq 3 \mathrm{~mm}(15.15 \%)$ and $\geq 4 \mathrm{~mm}$ (4.98\%) cutoff points. Overall, similar trends were observed for SICCT-BT and antibovine TB-Ab-positive/SICCT-BT-positive animals for the parameters considered. In all, $16.78 \%$ SIT-BT- and $12.73 \%$ SIT-BT-positive/antibovine TB-Ab-positive animals were detected (Figure 3). Among the SIT-BT reactors, over $98.59 \%, 61.23 \%$, and $10.38 \%$ were SICCT-BT reactors and $78.88 \%, 60.19 \%$, and $10.38 \%$ were SICCT-BTpositive/antibovine $\mathrm{TB}-\mathrm{Ab}$-positive animals at the $\geq 2 \mathrm{~mm}$, $\geq 3 \mathrm{~mm}$, and $\geq 4 \mathrm{~mm}$ cutoff points, respectively. Also, $84.07 \%$ SICCT-BT-positive/antibovine TB-Ab-positive animals were identified among the SIT-BT reactors, irrespective of the interpreting SICCT-BT cutoff point. SIT-AT positive reacting cattle was widespread in the study. 
TABle 3: Predictive values and likelihood ratios at the $\geq 2 \mathrm{~mm}, \geq 3 \mathrm{~mm}$, and $\geq 4 \mathrm{~mm}$ cutoff points for tuberculin skin tests and lateral flow assay of cattle reactors in Cameroon.

\begin{tabular}{|c|c|c|c|c|}
\hline \multirow{2}{*}{ Cutoff point } & \multicolumn{2}{|c|}{ Test predictive value; $\%$ (95\% CI) } & \multicolumn{2}{|c|}{ Diagnostic likelihood ratio; (95\% CI) } \\
\hline & Positive result & Negative result & $\mathrm{LR}+$ & LR- \\
\hline \multicolumn{5}{|c|}{ (a) For SICCT-BT test against antibovine TB Ab assay } \\
\hline$\geq 2 \mathrm{~mm}$ & $34.05(29.16-38.50)$ & $94.41(91.66-96.41)$ & $2.54(2.03-3.08)$ & $0.29(0.45-0.18)$ \\
\hline$\geq 3 \mathrm{~mm}$ & $29.55(25.32-33.13)$ & $97.58(95.42-98.79)$ & $2.77(2.24-3.27)$ & $0.16(0.32-0.08)$ \\
\hline$\geq 4 \mathrm{~mm}$ & $14.67(12.15-15.94)$ & $100(98.88-100)$ & $2.87(2.31-3.17)$ & $0 *(0.19-0)$ \\
\hline
\end{tabular}

\begin{tabular}{lllll}
\hline$\geq 4 \mathrm{~mm}$ & $33.03(28.13-37.61)$ & $93.53(90.87-95.58)$ & $2.45(1.94-2.99)$ & $0.34(0.50-0.23)$
\end{tabular}

* The perfect diagnostic test would be expected to have an LR- equal to zero and an LR+ equal to infinity (producing no false negatives, but detecting all negatives and detecting all positives, and generating no false positives). The best test therefore for excluding a disease is the one with the lowest LR- and the test with the highest LR+ is the best for detecting disease [28].

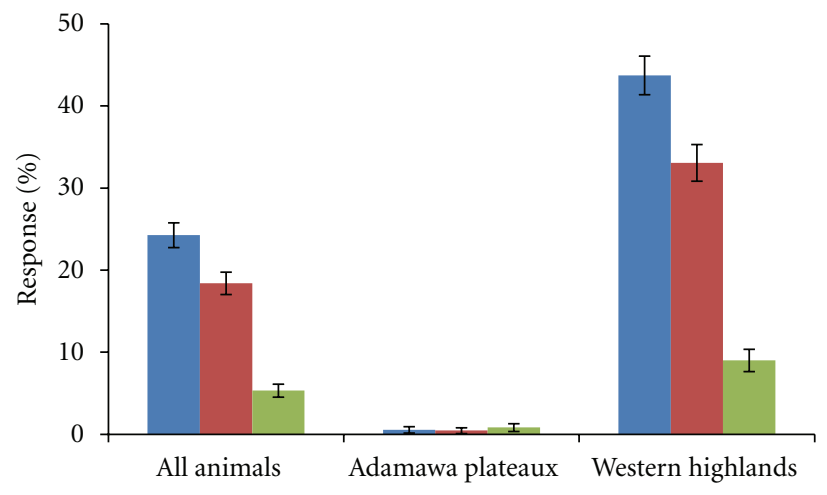

(a)

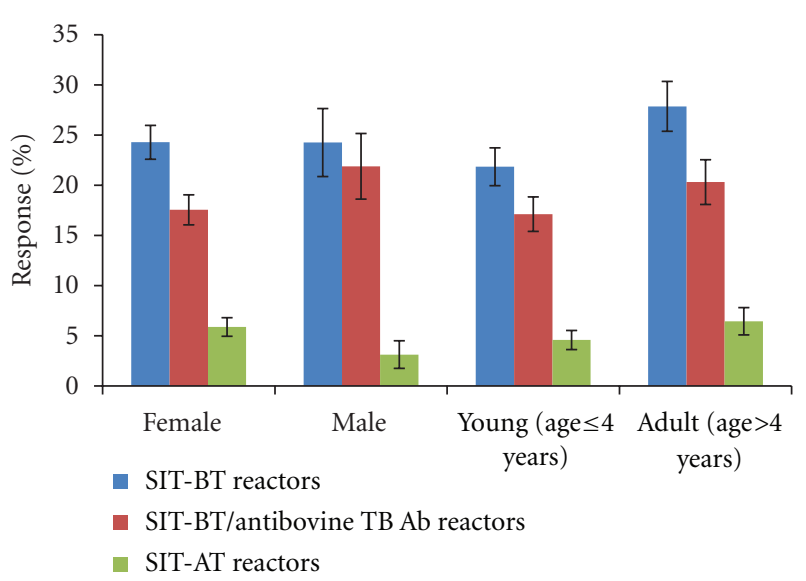

(c)

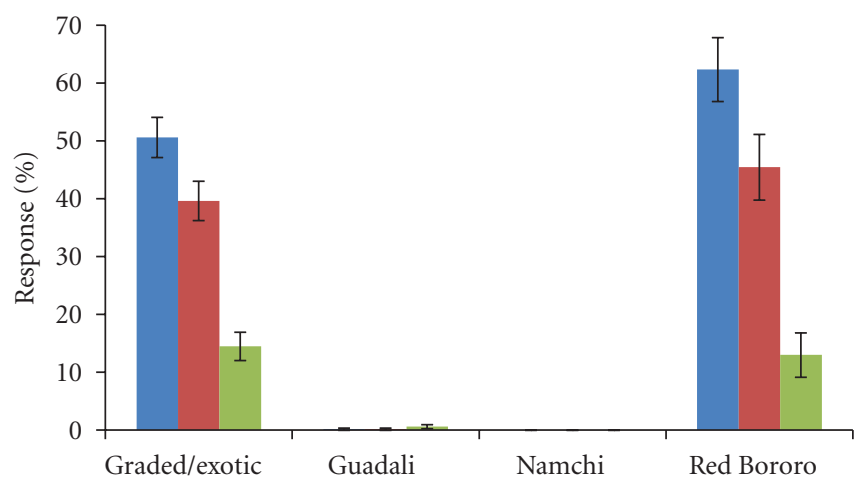

(b)

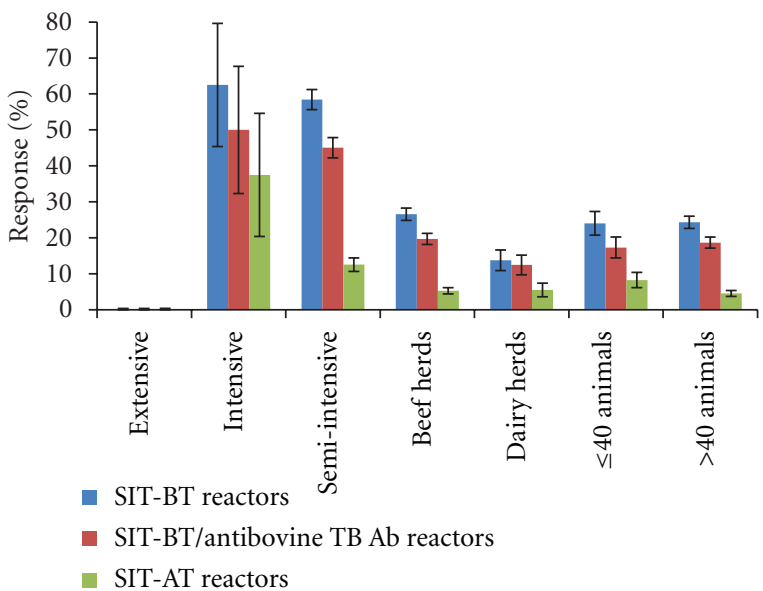

(d)

FIgure 3: Detection of antibovine TB antibody and SIT-BT reactors in 807 tested cattle according to (a) study location, (b) breed, (c) sex and age group, and (d) management systems and herd sizes.

Furthermore, antibovine $\mathrm{TB}$ Ab assay revealed that over 95\% (95\% CI: $75.1 \%-99.9 \%$ ) of the test herds had $\geq 1$ antibovine TB-Ab-positive animal, while SIT-BT and SICCTBT at $\geq 2 \mathrm{~mm}$ cutoff point gave nonsignificantly higher TST positive/antibovine $\mathrm{TB}$ Ab positive herds (36.84\%, (95\% CI: $16.3 \%-61.6 \%))$ than SICCT-BT at $\geq 3 \mathrm{~mm}$ and $\geq 4 \mathrm{~mm}$ (30\%, (95\% CI: $12.6 \%-56.5 \%)$ ) cutoff points. Indeed, the herd infection (i.e., $\geq 1$ TST positive animal) rates were
$35 \%$ (95\% CI: $15.4 \%-59.2 \%)$ for SIT-BT and SICCT-BT $\geq 2 \mathrm{~mm}$ cutoff point and 30\% (95\% CI: $11.9 \%-54.3 \%$ ) for the SICCT-BT at $\geq 3 \mathrm{~mm}$ and $\geq 4 \mathrm{~mm}$ cutoff points. Similarly, higher but comparable herd infection rates were obtained when severe interpretations were considered for complete TST screening of 1,381 cattle in 40 herds (i.e., for SICCT-BT: $40 \%$ (95\% CI: $24.9 \%-56.7 \%)$ at $\geq 3 \mathrm{~mm}$ and $\geq 4 \mathrm{~mm}$ cut-offs; $45 \%$ (95\% CI: $29.3 \%-61.5 \%$ ) at $\geq 2 \mathrm{~mm}$ 


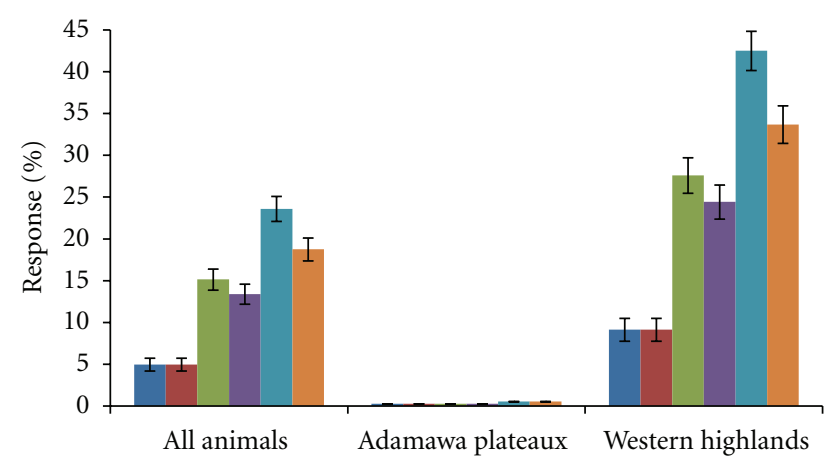

(a)

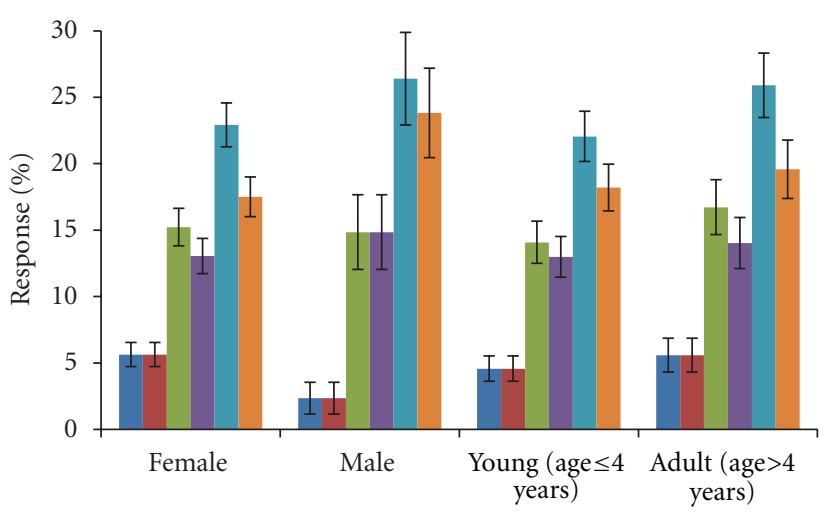

- SICCT-BT reactors at $\geq 4 \mathrm{~mm}$

- SICCT-BT/antibovine TB Ab reactors at $\geq 4 \mathrm{~mm}$

- SICCT-BT reactors at $\geq 3 \mathrm{~mm}$

- SICCT-BT/antibovine TB Ab reactors at $\geq 3 \mathrm{~mm}$

- SICCT-BT reactors at $\geq 2 \mathrm{~mm}$

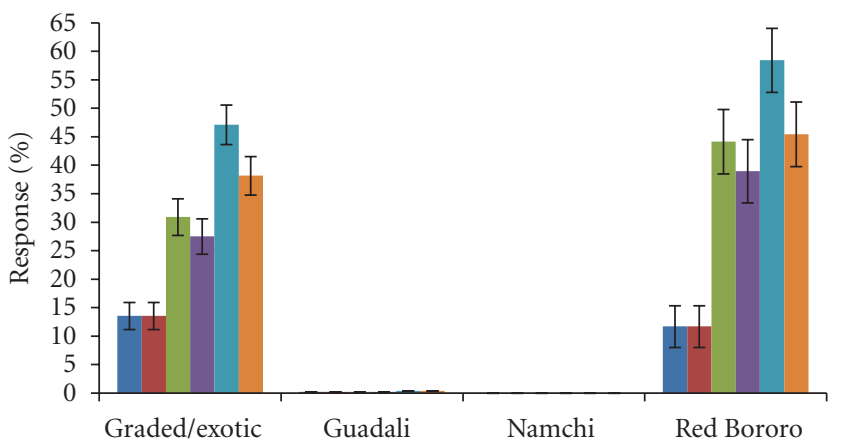

(b)

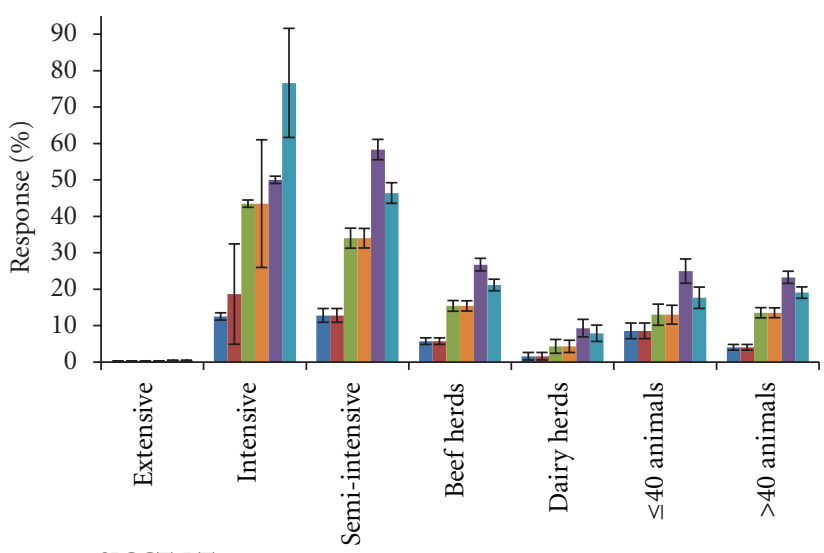

- SICCT-BT reactors at $\geq 4 \mathrm{~mm}$

- SICCT-BT/antibovine TB Ab reactors at $\geq 4 \mathrm{~mm}$

- SICCT-BT reactors at $\geq 3 \mathrm{~mm}$

- SICCT-BT/antibovine TB Ab reactors at $\geq 3 \mathrm{~mm}$

- SICCT-BT reactors at $\geq 2 \mathrm{~mm}$

(c)

(d)

FIGURE 4: Detection of antibovine TB antibody and SICCT-BT reactors in 807 tested cattle at the $\geq 4 \mathrm{~mm}, \geq 3 \mathrm{~mm}$, and $\geq 2 \mathrm{~mm}$ cutoff points according to (a) study location, (b) breed, (c) sex and age group, and (d) management systems and herd sizes.

cut-off and also $47.5 \%$ (95\% CI: 33.8\%-66.2\%) for SIT-BT). Also, significantly higher $(P<0.05)$ SICCT-BT- and SITBT-infected herds were recorded in the Western highlands (48.39\% (95\% CI: $30.2 \%-66.9 \%)$ at the SICCT-BT $\geq 4 \mathrm{~mm}$ and $\geq 3 \mathrm{~mm}$ cutoff points; $51.61 \%$ (95\% CI: $33.1 \%-69.8 \%$ ) at the SICCT-BT $\geq 2 \mathrm{~mm}$ cutoff point and $54.84 \%$ (95\% CI: $36 \%-72.7 \%$ ) for SIT-BT) than in the Adamawa plateaux (11.11\% (95\% CI: $24.9 \%-56.7 \%$ ) for the SICCT-BT $\geq 4 \mathrm{~mm}$ and $\geq 3 \mathrm{~mm}$ cutoff groups and $22.22 \%$ (95\% CI: $2.8 \%-60 \%$ ) for the SICCT-BT $\geq 2 \mathrm{~mm}$ cut-off and SIT-BT groups).

3.3. Prevalence Rates of Bovine Tuberculosis in Previously Tested Cattle at the Modified Cutoff Points. The TST survey in the year 2009 (2,853 cattle) and complete data of $2010(1,381$ cattle) were reanalysed using the predefined cutoff points (Tables 4 and 5). Overall, the prevalence rates and trends of bovine TB in both surveys were very similar. The differences in the prevalence of SICCT-BT reactors were significantly higher between the cutoff points $(\geq 4 \mathrm{~mm}$ versus $\geq 3 \mathrm{~mm}$ : $\chi^{2}=46.021 ; P \leq 0.001 ; \geq 4 \mathrm{~mm}$ versus $\geq 2 \mathrm{~mm}: \chi^{2}=64.015$; $P \leq 0.001 ; \geq 3 \mathrm{~mm}$ versus $\left.\geq 2 \mathrm{~mm}: \chi^{2}=16.056 ; P \leq 0.001\right)$. Age, sex, breed, animal site, and husbandry systems were significant $(P<0.05)$ risk factors to the epidemiological status of bovine TB in the regions.

\section{Discussion}

There is gross inadequacy in the implementation of the existing bovine TB control policy in Cameroon. Culling of TST reactors as part of a national animal disease control policy is not a routine practice due to political, economic, and social limitations. However, veterinarians continue to identify bovine TB lesions in slaughtered cattle across the country [33-35]. TB lesions have been detected in TST reactors at cutoff points less than the OIE-recommended optimal $4 \mathrm{~mm}$ cut-off $[8,9,15]$ and TST negative reactors [10]. TB lesions were also observed in TST doubtful and negative reactors in Mezam Division in the present study. Lack of knowledge on the actual magnitude and distribution of the disease, inadequate laboratories and field expertise, and politicoeconomic deficiencies are common factors that limit bovine TB control in most of Africa [36]. The current control approach in Cameroon is based on controlling animal movements, culling suspected bovine $\mathrm{TB}$ cases and 


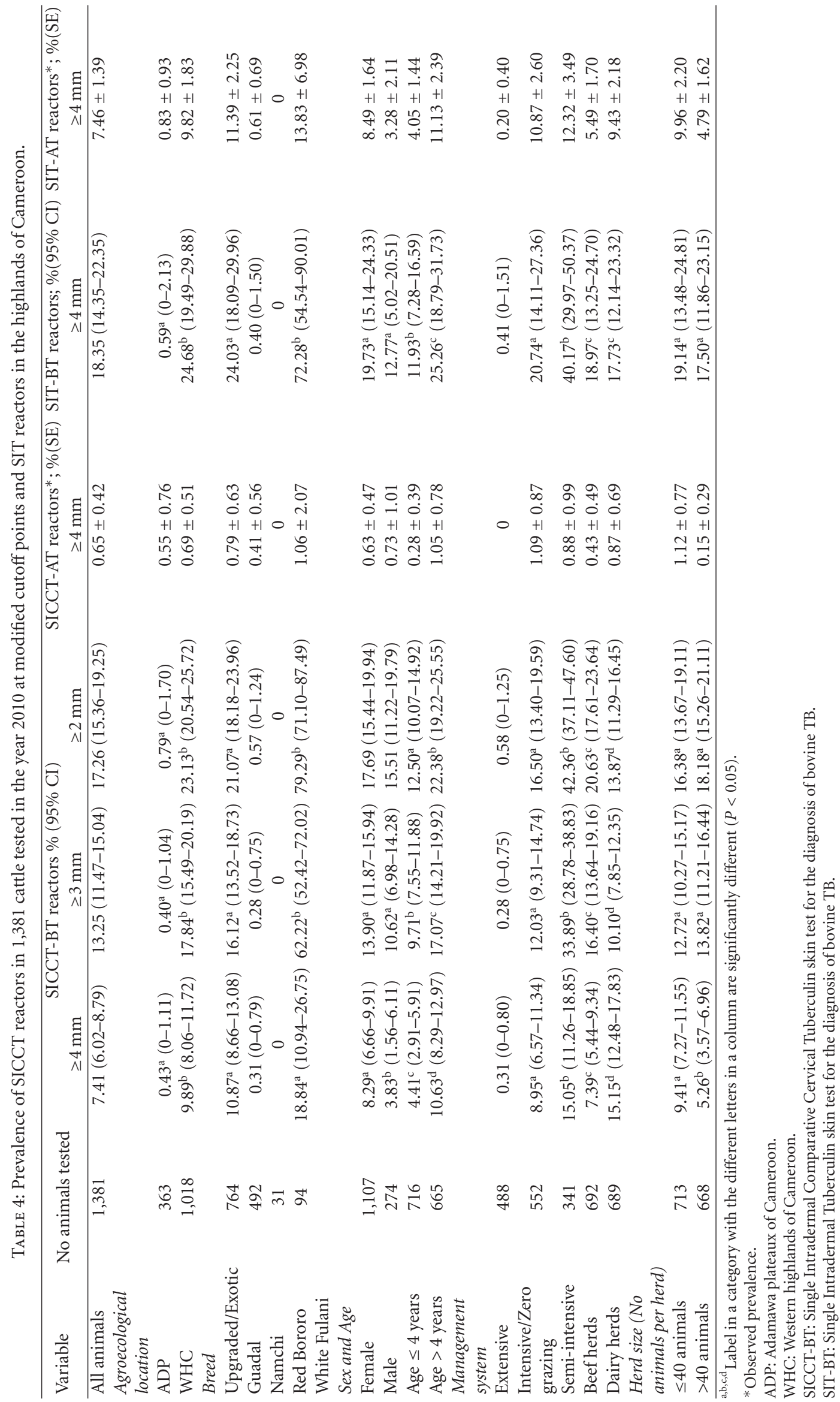


TABLE 5: Prevalence of SICCT-BT reactors in 2,853 cattle tested in the year 2009 at modified cutoff points in the highlands of Cameroon.

\begin{tabular}{|c|c|c|c|c|}
\hline \multirow{2}{*}{ Variable } & \multirow{2}{*}{ Animals tested } & \multicolumn{3}{|c|}{ SICCT-BT reactors \% (95\% CI) } \\
\hline & & $\geq 4 \mathrm{~mm}$ & $\geq 3 \mathrm{~mm}$ & $\geq 2 \mathrm{~mm}$ \\
\hline All animals & 2,853 & $7.48(6.51-8.44)$ & $11.52(10.35-12.69)$ & $12.92(11.69-11.15)$ \\
\hline \multicolumn{5}{|c|}{ Agroecological location } \\
\hline $\mathrm{ADP}$ & 727 & $4.10^{\mathrm{b}}(2.66-5.54)$ & $5.32^{\mathrm{b}}(3.69-6.95)$ & $7.07^{\mathrm{a}}(5.21-8.93)$ \\
\hline WHC & 2,126 & $8.63^{\mathrm{a}}(6.51-8.44)$ & $13.64^{\mathrm{a}}(12.18-15.10)$ & $14.92^{\mathrm{b}}(13.40-16.43)$ \\
\hline \multicolumn{5}{|l|}{ Breed } \\
\hline Upgraded/Exotic & 368 & $12.49^{\mathrm{a}}(9.12-15.87)$ & $19.39^{\mathrm{a}}(15.35-23.43)$ & $21.05^{\mathrm{a}}(16.88-25.21)$ \\
\hline Guadali & 1,317 & $6.01^{\mathrm{b}}(4.73-7.30)$ & $10.32^{\mathrm{b}}(8.68-11.96)$ & $12.32^{\mathrm{b}}(10.54-14.09)$ \\
\hline Namchi & 33 & 3.03 & 3.03 & 3.03 \\
\hline Red Bororo & 487 & $11.62^{\mathrm{a}}(8.77-14.46)$ & $15.64^{\mathrm{a}}(12.42-18.87)$ & $16.52^{\mathrm{a}}(13.22-19.82)$ \\
\hline White Fulani & 648 & $4.60^{\mathrm{b}}(2.99-6.22)$ & $6.72^{\mathrm{b}}(4.80-8.65)$ & $7.23^{\mathrm{b}}(5.24-9.23)$ \\
\hline \multicolumn{5}{|l|}{ Sex and Age } \\
\hline Female & 2,212 & $7.73^{\mathrm{a}}(6.62-8.85)$ & $12.30^{\mathrm{a}}(10.93-13.67)$ & $13.92^{\mathrm{a}}(12.48-15.36)$ \\
\hline Male & 641 & $6.60^{\mathrm{a}}(4.67-8.52)$ & $8.83^{\mathrm{b}}(6.63-11.02)$ & $9.45^{\mathrm{b}}(7.19-11.72)$ \\
\hline Age $\leq 4$ years & 1,481 & $5.82^{\mathrm{b}}(4.63-7.01)$ & $8.40^{c}(6.99-9.82)$ & $9.72^{\mathrm{c}}(8.21-11.22)$ \\
\hline Age $>4$ years & 1,372 & $9.27^{\mathrm{c}}(7.73-10.80)$ & $14.88^{\mathrm{d}}(13.00-16.77)$ & $16.37^{\mathrm{d}}(14.41-18.33)$ \\
\hline \multicolumn{5}{|l|}{ Management system } \\
\hline Extensive & 1510 & $6.77^{\mathrm{a}}(5.50-8.03)$ & $9.32^{\mathrm{a}}(7.85-10.78)$ & $9.93^{\mathrm{a}}(8.42-11.44)$ \\
\hline Intensive & 138 & $6.38^{\mathrm{a}}(2.03-10.46)$ & $17.62^{\mathrm{b}}(11.27-23.98)$ & $19.81^{\mathrm{b}}(13.16-26.46)$ \\
\hline Semi-intensive & 1205 & $8.49^{\mathrm{a}}(6.92-10.07)$ & $13.58^{\mathrm{b}}(11.64-15.51)$ & $15.87^{\mathrm{b}}(13.81-17.93)$ \\
\hline Beef herds & 2,357 & $8.16^{\mathrm{b}}(7.05-9.26)$ & $10.78^{\mathrm{c}}(9.53-12.03)$ & $11.71^{\mathrm{c}}(10.41-13.00)$ \\
\hline Dairy herds & 496 & $4.24^{\mathrm{c}}(2.47-6.02)$ & $15.03^{\mathrm{d}}(11.88-18.17)$ & $18.67^{\mathrm{d}}(15.24-22.10)$ \\
\hline \multicolumn{5}{|c|}{ Herd size (No animals per herd) } \\
\hline$\leq 40$ animals & 1,325 & $9.19^{a}(7.64-10.75)$ & $11.98^{\mathrm{a}}(10.23-13.72)$ & $13.51^{\mathrm{a}}(11.67-15.35)$ \\
\hline$>40$ animals & 1,528 & $5.99^{\mathrm{b}}(4.80-7.18)$ & $11.12^{\mathrm{a}}(9.55-12.70)$ & $12.40^{\mathrm{a}}(10.75-14.06)$ \\
\hline
\end{tabular}

a,b,c,d label in a category with different letters in a column are significantly different $(P<0.05)$.

SICCT-BT: Single Intradermal Comparative Cervical Tuberculin skin test for the diagnosis of bovine tuberculosis.

carcass condemnation (partial or whole) at meat inspection [37]. Apparently, the strategies were designed to reduce the general prevalence and monitor spread of the disease in livestock. TST is presently a passive component of Cameroon's government strategy to control bovine TB which is of major concern to the veterinary and medical services.

Maximum detection of bovine TB in cattle populations in Cameroon is vital to understand its epidemiology and zoonotic potentials and also achieve significant reduction and control of the disease in livestock. Cell-mediated immune responses develop early after bovine TB infection in cattle while antibody responses may not become obvious until later and at advanced stages of the disease, when cell mediated reactions (TST reactions) are waning [38-40]. TST can boost antibody responses in $M$. bovis infected cattle and emphasizes the importance of timing of collection of blood samples on the interpretation the test [38]. In this study, the antibovine TB antibody detection (Anigen lateral-flow assay) that employed recombinant $M$. bovis MPB70 antigen as capture and detector was conducted prior to TST. This antibovine TB antibody test kit has a sensitivity of $90 \%$ against bovine $\mathrm{TB}$ confirmed by bacterial isolation and a sensitivity of $85.1 \%$ and specificity of $98.6 \%$ against TST [41]. Also using the Anigen lateral-flow assay, Whelan et al.
[42] achieved a sensitivity of $84 \%$ and a specificity of $84.2 \%$ for serological diagnosis of $M$. bovis infection in cattle. Similar and relatively high sensitivity $(86.5 \%$ and $84.6 \%)$ and specificity $(83.8 \%$ and $91.4 \%)$ have been reported with other lateral flow techniques (CervidTB STAT-PAK and DPP VetTB assays, resp.) for the rapid diagnosis of bovine TB in farmed Red deers [43]. Furthermore, a sensitivity of $89.6 \%$ and specificity of $90.4 \%$ were achieved in the diagnosis of M. bovis infection in Eurasian wild boar using the DPP VetTB assay (based on combining two separate test antigens) [44]. However, the specificity of these test kits could be affected by cross-reacting members of the M. avium complex $[43,44]$, and high false positive results were observed when a commercial multiantigen lateral flow assay was performed in dairy cattle [45]. Nonetheless, significantly higher specificity of $98.4 \%$ and sensitivity of $93.1 \%$ in the diagnosis of bovine TB in cattle have been obtained for multiplex immunoassay based on a combination of antigens compared to those of assays based on a single antigen [22, 42]. The TST accuracy against postmortem detection of $\mathrm{TB}$ lesions revealed a sensitivity of $86 \%$ and specificity of $90 \%$ for SIT-BT [12], while sensitivity values of $69 \%, 65 \%$, and $59 \%$ at SICCT-BT $\geq 2 \mathrm{~mm}, \geq 3 \mathrm{~mm}$, and $\geq 4 \mathrm{~mm}$ cutoff points and a specificity of $97 \%$ at these cutoff points have been reported [9]. The 
lack of a well-established gold standard in this study was a key problem in calculating the sensitivity and specificity of the lateral flow assay and TST at the modified cutoff points.

The findings of this study suggest that TST at any cutoff point could be used to detect bovine TB in cattle and the test accuracy increased with increase in cut-off value. Cattle presenting differential SICCT-BT skin thickness of less than $4 \mathrm{~mm}$ in Cameroon should therefore not be excluded that they are negative for bovine TB. These animals may be infected but low reacting or not reacting at all if their immune systems were not stimulated enough for a positive response at the $\geq 4 \mathrm{~mm}$ cutoff point $[46,47]$ due to conditions such as stress that compromise immune function [48]. Also, the animals may have been sensitized to environmental mycobacteria [38]. Furthermore, delayed hypersensitivity to tuberculin may not develop for a period of 3-6 weeks following infection $[3,10]$. Delaying TST of a herd/animal suspected to have been in contact very recently with infected animals in order to reduce the probability of false-negatives has been suggested [10] since it is unlikely that the control and eradication of TB from a herd will be achieved with only a single tuberculin test [3]. In this study, maximum positive prediction values and negative likelihood ratio were observed at the SICCT-BT $\geq 2 \mathrm{~mm}$ cutoff point and maximum negative prediction and positive likelihood ratio at the $\geq 4 \mathrm{~mm}$ cutoff point. The findings also revealed that 31 cattle (over $3.84 \%$ ) considered as SICCTBT doubtful reactors at the $\geq 4 \mathrm{~mm}$ cutoff point could be identified as positive bovine TB cases at the $\geq 3 \mathrm{~mm}$ and $\geq 2 \mathrm{~mm}$ cutoff points. The poor to fair agreements recorded suggested that severe interpretation of TST (i.e., decreasing skin response cut-off values) improved the agreement between TST and the lateral flow assay to detect TST positive reactors. The prevalence rates at the modified cutoff points could have influenced the estimated Kappa values. However, low kappa values have been obtained between good diagnostic and negatively correlated tests [28]. The poor correlation between comparative TST at the $\geq 4 \mathrm{~mm}$ cutoff point and antibovine TB antibody test results in the study was not unexpected. Therefore, the importance of determining appropriate localised TST cut-off values supported by validated methods in Cameroon cannot be overemphasized.

Though it is essential that tuberculin of sufficient potency to produce a reaction in the maximum number of infected animals is essential, a tuberculin of potency greater than that to which the majority of infected animals will respond has been proposed in TST [10]. However, Good and Duignan [10] had warned that highly potent tuberculin tends to increase the frequency of reactions associated with crosssensitisations arising from other organisms such as the human and avian types (M. tuberculosis and M. avium, resp.) and other (nonpathogenic) mycobacteria. Nonspecific responses in TST due to atypical or environmental mycobacteria have been widely reported [2, 3, 49-51]. Indeed, Lesslie et al. [52-54] recorded hypersensitivity responses to avian tuberculin that was equal or higher than responses to bovine tuberculin in cattle naturally infected with $M$. bovis and presenting visible lesions at slaughter. Therefore, severe interpretations of TST reactions should be employed when EU- and OIE-recommended tuberculin preparations are used in bovine TB endemic regions and environments where multiple mycobacteria are coexisting. The findings of this study agree with Martrenchar et al. [23] who reported high frequency of atypical mycobacteria which severely limited the reliability of SIT-BT and SICCT-BT results at the OIE-recommended $4 \mathrm{~mm}$ cutoff point in Northern Cameroon. Severe interpretations of TST results in the study revealed that many SIT-BT positive and SICCT-BT doubtful responses at $\geq 4 \mathrm{~mm}$ cutoff point could be appropriately identified as bovine TB cases at reduced cutoff points (some Excess D4 and Excess D3 reactors). The high detection of TST and antibovine TB antibody positive herds irrespective of TST cutoff point and findings of circulating antibovine TB antibody could suggest that the cattle were widely exposed to and affected bovine TB and other mycobacterial infections.

In this study, reducing the cutoff point from $\geq 4 \mathrm{~mm}$ improved the ante mortem detection of bovine $\mathrm{TB}$ in cattle using SICCT-BT and antibovine TB Ab tests. Overall, the maximum test ability was realized at $\geq 3 \mathrm{~mm}$ cutoff point and the best SICCT-BT positive predictive value was at $\geq 2 \mathrm{~mm}$ cutoff point. These findings revealed that interpreting SICCT-BT at the $\geq 2 \mathrm{~mm}$ cutoff point, and not at the $\geq 3 \mathrm{~mm}$ or $\geq 4 \mathrm{~mm}$ cutoff points, was beneficial from a public health perspective. However, there would be concrete risk of unnecessarily identifying more cattle at severe TST interpretations. This study cannot exclude that some SICCTBT doubtful reactors at the $\geq 3 \mathrm{~mm}$ and the $\geq 4 \mathrm{~mm}$ cutoff points were infected cases detected at the $\geq 2 \mathrm{~mm}$ cutoff point. The application of the SICCT-BT $\geq 2 \mathrm{~mm}$ cutoff point should be considered in cattle in the agro-ecological highland environments of Cameroon for greater detection of bovine TB. Severe TST interpretation would be vital to effective control of the disease and reduction of its zoonotic risks to public health and food safety in the country.

\section{Conclusion}

The TST and antibovine TB antibody tests when used in parallel offered improved detection of bovine TB compared to individual tests. Bovine $\mathrm{TB}$ was detected at all the cutoff points and there were strong associations between both methods in the highlands of Cameroon. The best test performance was realized at the $\geq 3 \mathrm{~mm}$ cutoff point. However, interpreting SICCT-BT at $\geq 2 \mathrm{~mm}$ cutoff point was more strategic from a public health context since more affected cases would be predicted. The study revealed that the prevalence of bovine TB was high and atypical mycobacteria infection was widespread in the regions. Bovine TB-infected cattle which maybe anergic due to age, malnutrition, and/or suffering from concurrent diseases such as internal and external parasitosis (common scenarios in the study regions) could be detected at severe SICCT-BT interpretation. Their delayed hypersensitivity responses to tuberculin would be limited and cannot express the full OIE-recommended $\geq 4 \mathrm{~mm}$ cutoff point. However, it is important to investigate the performance of TST at modified cutoff points against 
defined bovine TB status confirmed by postmortem examination and culture of TB lesions in reacting animals in the Cameroon environments.

\section{Acknowledgments}

This paper was supported by a Ph.D. grant of the Commonwealth Scholarship Commission in UK. The authors are also grateful to the Staff of MINEPIA and cattle professionals of the Northwest and Adamawa regions of Cameroon for their generous cooperation and for the support of IRAD-Wakwa.

\section{References}

[1] R. de la Rua-Domenech, T. Goodchild, M. Vordermeier, and R. Clifton-Hadley, "Ante mortem diagnosis of Bovine Tuberculosis: the significance of unconfirmed test reactors," Government Veterinary Journal, vol. 16, no. 1, pp. 65-71, 2006.

[2] R. de la Rua-Domenech, A. T. Goodchild, H. M. Vordermeier, R. G. Hewinson, K. H. Christiansen, and R. S. Clifton-Hadley, "Ante mortem diagnosis of tuberculosis in cattle: a review of the tuberculin tests, $\gamma$-interferon assay and other ancillary diagnostic techniques," Research in Veterinary Science, vol. 81, no. 2, pp. 190-210, 2006.

[3] World Organisation for Animal Health (OIE), Manual of Diagnostic Tests and Vaccines for Terrestrial Animals 2009. OIE Terrestrial Manual 2008, World Organisation for Animal Health, Paris, France, 2009.

[4] M. L. Monaghan, M. L. Doherty, J. D. Collins, J. F. Kazda, and P. J. Quinn, "The tuberculin test," Veterinary Microbiology, vol. 40, no. 1-2, pp. 111-124, 1994.

[5] J. Francis, C. L. Choi, and A. J. Frost, "The diagnosis of tuberculosis in cattle with special reference to bovine PPD tuberculin," Australian Veterinary Journal, vol. 49, no. 5, pp. 246-251, 1973.

[6] B. M. Buddle, P. G. Livingstone, and G. W. de Lisle, "Advances in ante-mortem diagnosis of tuberculosis in cattle," New Zealand Veterinary Journal, vol. 57, no. 4, pp. 173-180, 2009.

[7] B. N. R. Ngandolo, B. Müller, C. Diguimbaye-Djaïbe et al., "Comparative assessment of fluorescence polarization and tuberculin skin testing for the diagnosis of bovine tuberculosis in Chadian cattle," Preventive Veterinary Medicine, vol. 89, no. 1-2, pp. 81-89, 2009.

[8] R. R. Kazwala, D. M. Kambarage, C. J. Daborn, J. Nyange, S. F. H. Jiwa, and J. M. Sharp, "Risk factors associated with the occurrence of bovine tuberculosis in cattle in the Southern Highlands of Tanzania," Veterinary Research Communications, vol. 25, no. 8, pp. 609-614, 2001.

[9] G. Ameni, G. Hewinson, A. Aseffa, D. Young, and M. Vordermeier, "Appraisal of interpretation criteria for the comparative intradermal tuberculin test for diagnosis of tuberculosis in cattle in central Ethiopia," Clinical and Vaccine Immunology, vol. 15, no. 8, pp. 1272-1276, 2008.

[10] M. Good and A. Duignan, "Perspectives on the history of Bovine $\mathrm{TB}$ and the role of tuberculin in Bovine $\mathrm{TB}$ eradication," Veterinary Medicine International, vol. 2011, Article ID 410470, 11 pages, 2011.

[11] M. V. Palmer and W. R. Waters, "Bovine tuberculosis and the establishment of an eradication program in the United States: role of veterinarians," Veterinary Medicine International, vol. 2011, Article ID 816345, 12 pages, 2011.
[12] J. M. Pollock, J. McNair, H. Bassett et al., "Specific delayed-type hypersensitivity responses to ESAT-6 identify tuberculosis-infected cattle," Journal of Clinical Microbiology, vol. 41, no. 5, pp. 1856-1860, 2003.

[13] M. Amadori, S. Tameni, P. Scaccaglia, S. Cavirani, I. L. Archetti, and R. Q. Giandomenico, "Antibody tests for identification of Mycobacterium bovis- infected bovine herds," Journal of Clinical Microbiology, vol. 36, no. 2, pp. 566-568, 1998.

[14] M. L. Thom, J. C. Hope, M. McAulay et al., "The effect of tuberculin testing on the development of cell-mediated immune responses during Mycobacterium bovis infection," Veterinary Immunology and Immunopathology, vol. 114, no. 12, pp. 25-36, 2006.

[15] G. Ameni, H. Miörner, F. Roger, and M. Tibbo, "Comparison between comparative tuberculin and gamma-interferon tests for the diagnosis of bovine tuberculosis in Ethiopia," Tropical Animal Health and Production, vol. 32, no. 5, pp. 267-276, 2000.

[16] R. Quirin, V. Rasolofo, R. Andriambololona et al., "Validity of intradermal tuberculin testing for the screening of bovine tuberculosis in Madagascar," Onderstepoort Journal of Veterinary Research, vol. 68, no. 3, pp. 231-238, 2001.

[17] K. Lyashchenko, A. O. Whelan, R. Greenwald et al., "Association of Tuberculin-Boosted Antibody Responses with Pathology and Cell-Mediated Immunity in Cattle Vaccinated with Mycobacterium bovis BCG and Infected with M. bovis," Infection and Immunity, vol. 72, no. 5, pp. 2462-2467, 2004.

[18] K. P. Lyashchenko, J. M. Pollock, R. Colangeli, and M. L. Gennaro, "Diversity of antigen recognition by serum antibodies in experimental bovine tuberculosis," Infection and Immunity, vol. 66, no. 11, pp. 5344-5349, 1998.

[19] G. Ameni, A. Aseffa, G. Hewinson, and M. Vordermeier, "Comparison of different testing schemes to increase the detection Mycobacterium bovis infection in Ethiopian cattle," Tropical Animal Health and Production, vol. 42, no. 3, pp. 375383, 2010.

[20] J. M. Pollock, M. D. Welsh, and J. McNair, "Immune responses in bovine tuberculosis: towards new strategies for the diagnosis and control of disease," Veterinary Immunology and Immunopathology, vol. 108, no. 1-2, pp. 37-43, 2005.

[21] U. Wernery, J. Kinne, K. L. Jahans et al., "Tuberculosis outbreak in a dromedary racing herd and rapid serological detection of infected camels," Veterinary Microbiology, vol. 122, no. 1-2, pp. 108-115, 2007.

[22] W. R. Waters, M. V. Palmer, T. C. Thacker et al., "Early antibody responses to experimental Mycobacterium bovis infection of cattle," Clinical and Vaccine Immunology, vol. 13, no. 6, pp. 648-654, 2006.

[23] A. Martrenchar, B. M. Njanpop, A. Yaya, A. Njoya, and J. J. Tulasne, "Problems associated with tuberculosis and brucellosis skin-test methods in northern Cameroon," Preventive Veterinary Medicine, vol. 15, no. 2-3, pp. 221-229, 1993.

[24] P. Merlin and P. Tsangueu, "Incidence de la tuberculose bovin dans le nord ouest du Cameroun," Revue Scientifique et Technologique, vol. 1, no. 4, pp. 89-93, 1985.

[25] P. K. Muchaal, Assessment of Bovine Tuberculosis (Mycobacterium bovis) and Risk Factors of Transmission in the PeriUrban Centres of Bamenda, Northwest Province (Cameroon), in Urban Agriculture and Zoonoses in West Africa: An Assessment of the Potential Impact on Public Health, The International Development Research Centre (IDRC), Ottawa, Canada, 2002.

[26] A. N. Nfi and C. Ndi, "Bovine tuberculosis at the animal research antenna (ARZ) Bangangte, Western province, 
Cameroon," Bulletion of Animal Production and Health in Africa, vol. 45, pp. 1-3, 1997.

[27] V. N. Tanya, J. N. S. Sallah, and K. R. Tayou, "Screening for bovine tuberculosis at Wakwa," Revue Scientifique et Technologique, vol. 1, no. 2, pp. 65-68, 1985.

[28] M. Thrusfield, Veterinary Epidemiology, Blackwell Science, Oxford, UK, 3rd edition, 2007.

[29] E. Costello, J. W. A. Egan, F. C. Quigley, and P. F. O’Reilly, "Performance of the single intradermal comparative tuberculin test in identifying cattle with tuberculous lesions in Irish herds," Veterinary Record, vol. 141, no. 9, pp. 222-224, 1997.

[30] G. M. Shirima, R. R. Kazwala, and D. M. Kambarage, "Prevalence of bovine tuberculosis in cattle in different farming systems in the eastern zone of Tanzania," Preventive Veterinary Medicine, vol. 57, no. 3, pp. 167-172, 2003.

[31] M. Greiner and I. A. Gardner, "Application of diagnostic tests in veterinary epidemiologic studies," Preventive Veterinary Medicine, vol. 45, no. 1-2, pp. 43-59, 2000.

[32] A. Petrie and P. Watson, Statistics for Veterinary and Animal Science, Blackwell Science, Oxford, UK, 1999.

[33] J. Awah-Ndukum, A. C. Kudi, G. Bradley, I. N. Ane-Anyangwe, S. Fon-Tebug, and J. Tchoumboue, "Prevalence of bovine tuberculosis in abattoirs of the Littoral and Western highland regions of Cameroon: a cause for public health concern," Veterinary Medicine International, vol. 2010, Article ID 495015, 8 pages, 2010.

[34] J. Awah-Ndukum, J. Tchoumboue, and A. T. Niba, "Prevalence of bovine tuberculosis at the SODEPA Douala abattoir, Cameroon (1995-2003)," Cameroon Journal of Experimental Biology, vol. 1, no. 2, pp. 116-120, 2005.

[35] A. Doufissa, "L'élevage bovin dans le M’béré," MINEPIA Report, Ministry of Livestock, Fishery and Animal Industries, Yaounde, Cameroon, 1993.

[36] African Union/Interafrican Bureau for Animal Resources Nairobi (AU/IBAR), Pan African Animal Health Yearbook 2006, African Union/Interafrican Bureau for Animal Resources Nairobi, Nairobi, Kenya, 2006.

[37] MINEPIA, "La stratégie sectoriel de l'élevage, des peches et industries animales," in Cabinet Management 2000 MINEPIA, A. Doufissa, Ed., Ministry of Livestock, Fisheries and Animal Industries, Yaounde, Yaounde, Cameroon, 2002.

[38] M. V. Palmer, W. R. Waters, T. C. Thacker, R. Greenwald, J. Esfandiari, and K. P. Lyashchenko, "Effects of different tuberculin skin-testing regimens on gamma interferon and antibody responses in cattle experimentally infected with Mycobacterium bovis," Clinical and Vaccine Immunology, vol. 13, no. 3, pp. 387-394, 2006.

[39] V. Ritacco, B. Lopez, I. N. De Kantor, L. Barrera, F. Errico, and A. Nader, "Reciprocal cellular and humoral immune responses in bovine tuberculosis," Research in Veterinary Science, vol. 50, no. 3, pp. 365-367, 1991.

[40] M. Vordermeier, S. V. Gordon, and R. G. Hewinson, "Mycobacterium bovis antigens for the differential diagnosis of vaccinated and infected cattle," Veterinary Microbiology, vol. 151, no. 1-2, pp. 8-13, 2011.

[41] Bovine TB Ab, Anigen Rapid Bovine TB Ab Test Kit; Cat.No :RB 23-02, in Diagnostic Test Kits for Industrial Animals: Bionote Product catalog; Third Edition CIA03-03, BioNote Inc.: Gyeonggi-do, Korea.

[42] C. Whelan, E. Shuralev, G. O'Keeffe et al., "Multiplex immunoassay for serological diagnosis of Mycobacterium bovis infection in cattle," Clinical and Vaccine Immunology, vol. 15, no. 12, pp. 1834-1838, 2008.
[43] B. M. Buddle, T. Wilson, M. Denis et al., "Sensitivity, specificity, and confounding factors of novel serological tests used for the rapid diagnosis of bovine tuberculosis in farmed red deer (Cervus elaphus)," Clinical and Vaccine Immunology, vol. 17, no. 4, pp. 626-630, 2010.

[44] M. Boadella, K. Lyashchenko, R. Greenwald et al., "Serologic tests for detecting antibodies against Mycobacterium bovis and Mycobacterium avium subspecies paratuberculosis in Eurasian wild boar (Sus scrofa scrofa)," Journal of Veterinary Diagnostic Investigation, vol. 23, no. 1, pp. 77-83, 2011.

[45] H. R. Bermúdez, E. T. Renteria, B. G. Medina, S. Hori-Oshima, A. de la Mora Valle, and V. G. Lopez, "Evaluation of a lateral flow assay for the diagnosis of Mycobacterium bovis infection in dairy cattle," Journal of Immunoassay and Immunochemistry, vol. 33, no. 1, pp. 59-65, 2012.

[46] G. Ameni and G. Medhin, "Effect of Gastro-intestinal Parasitosis on Tuberculin Test for the Diagnosis of Bovine Tuberculosis," Journal of Applied Animal Research, vol. 18, no. 2, pp. 221-224, 2000.

[47] F. O. Inangolet, B. Demelash, J. Oloya, J. Opuda-Asibo, and E. Skjerve, "A cross-sectional study of bovine tuberculosis in the transhumant and agro-pastoral cattle herds in the border areas of Katakwi and Moroto districts, Uganda," Tropical Animal Health and Production, vol. 40, no. 7, pp. 501-508, 2008.

[48] C. O. Thoen, P. A. Lobue, D. A. Enarson, J. B. Kaneene, and I. N. de Kantor, "Tuberculosis: a re-emerging disease of animals and humans," Veterinaria Italiana, vol. 45, no. 1, pp. 135-181, 2009.

[49] F. Biet, M. L. Boschiroli, M. F. Thorel, and L. A. Guilloteau, "Zoonotic aspects of Mycobacterium bovis and Mycobacterium avium-intracellulare complex (MAC)," Veterinary Research, vol. 36, no. 3, pp. 411-436, 2005.

[50] J. Oloya, J. Opuda-Asibo, B. Djønne et al., "Responses to tuberculin among Zebu cattle in the transhumance regions of Karamoja and Nakasongola district of Uganda," Tropical Animal Health and Production, vol. 38, no. 4, pp. 275-283, 2006.

[51] C. J. C. Phillips, C. R. W. Foster, P. A. Morris, and R. Teverson, "The transmission of Mycobacterium bovis infection to cattle," Research in Veterinary Science, vol. 74, no. 1, pp. 1-15, 2003.

[52] I. W. Lesslie and C. N. Herbert, "Comparison of the specificity of human and bovine tuberculin PPF for testing cattle. 3. National trial in Great Britain," Veterinary Record, vol. 96, no. 15, pp. 338-341, 1975.

[53] I. W. Lesslie, C. N. Herbert, and D. N. Barnett, "Comparison of the specificity of human and bovine tuberculin PPD for testing cattle. 2. South-eastern England," Veterinary Record, vol. 96, no. 15, pp. 335-338, 1975.

[54] I. W. Lesslie and C. N. Herbert, "Comparison of the specificty of human and bovine tuberculin PPD for testing cattle. 1Republic of Ireland," Veterinary Record, vol. 96, no. 15, pp. 332-334, 1975. 

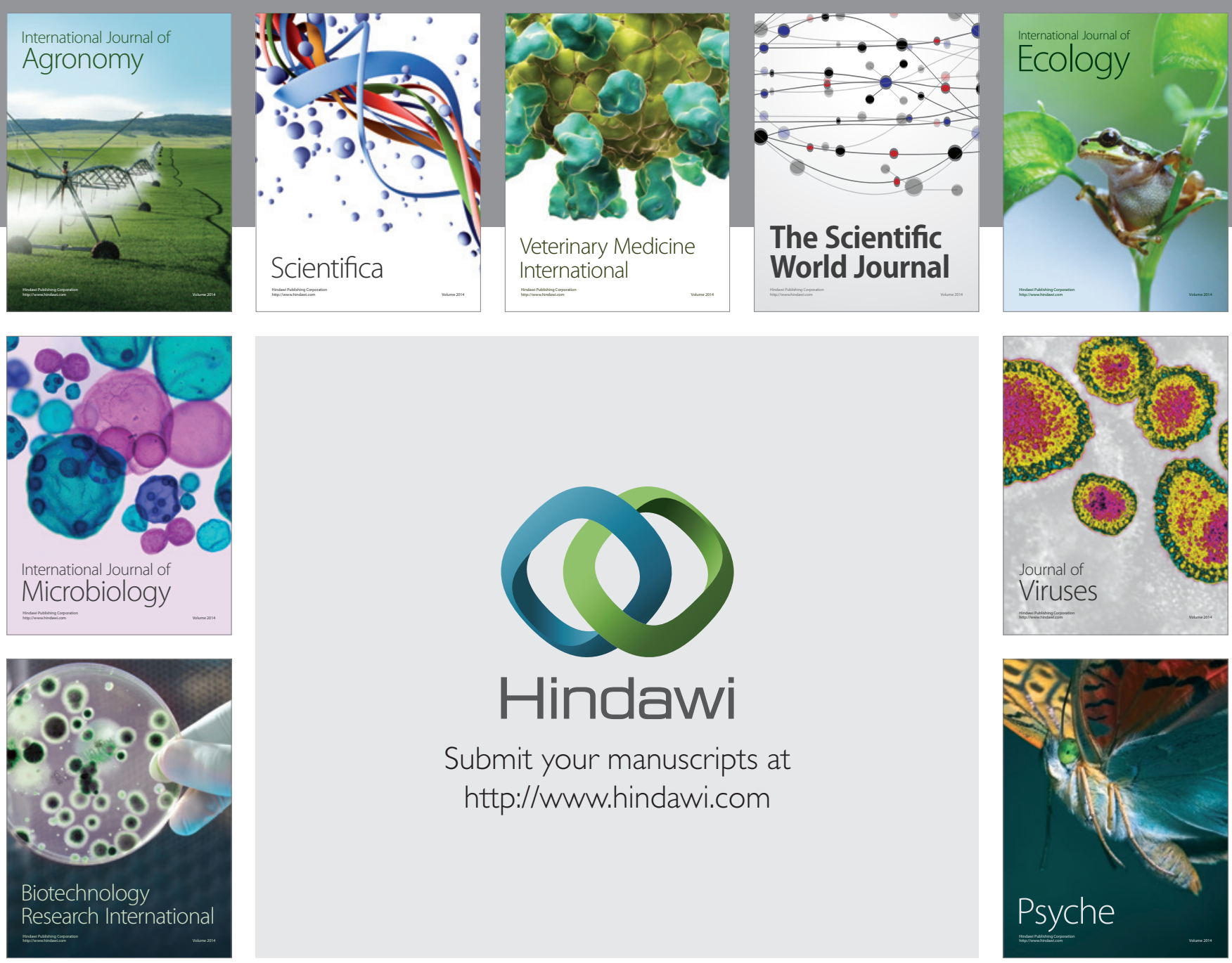

Submit your manuscripts at

http://www.hindawi.com
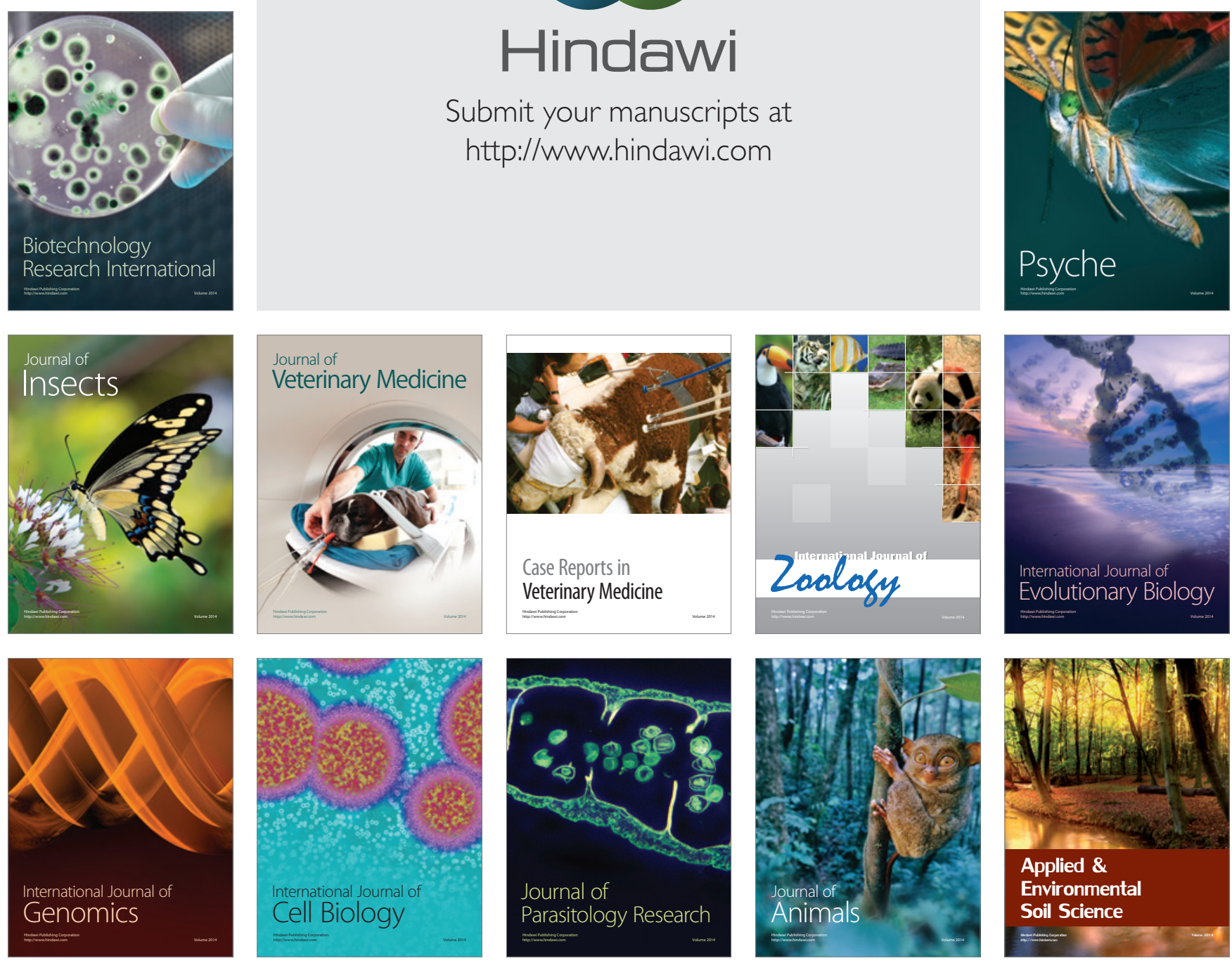